\title{
Management Of Abutment Failure Of Mandibular Implant Supported Over Denture: A Case Report
}

\author{
Reshma Premkumar ${ }^{1}$, Gilsa K Vasunni ${ }^{2}$, Mehul R Mahesh ${ }^{3}$, Rasmi M $^{4}$, Prasanth \\ Manohar B ${ }^{5}$ \\ ${ }^{1}$ Junior Resident, Dept. of Prosthodontics, Govt. Dental College, Kozhikode \\ ${ }^{2}$ Principal, Govt. Dental College, Kozhikode \\ ${ }^{3}$ Asso. Prof, Dept. of Prosthodontics, Govt. Dental College, Kozhikode \\ ${ }^{4}$ Junior Resident, Dept. of Prosthodontics, Govt. Dental College, Kozhikode \\ ${ }^{5}$ Senior Resident, Dept. of Prosthodontics, Govt. Dental College, Kozhikode
}

\begin{abstract}
In contemporary implant and prosthodontic practice, high levels of surgical and biologic success rates have been achieved. However, mechanical and technical complications continue to exist. Of these, one of the biggest challenges to the clinician is the conservative retrieval of fractured screw fragments from within the implants and/or abutments. This clinical report describes a relatively simple technique for retrieval of fractured abutment of Mandibular Implant Supported Overdenture.
\end{abstract}

Keywords: Implant Supported Overdenture, Ball Abutment, Abutment Fracture, Screw Retrieval.

\section{Introduction}

The use of dental implants has enabled the fabrication of restorations and improved the esthetic predictability of treatment. However, at any point during rehabilitation and maintenance, complications and failure can occur. Screw fracture is a complication of implant-supported restorations. Misch states prosthetic screw fracture occurs approximately $4 \%$ of the time and abutment screw fracture $2 \%$ of the time. Fractures usually occur at the junction of the screw head and screw shank or at the junction of the screw shank and screw thread. Once an abutment fracture has occurred, the fractured screw segment inside the implant must be removed. The implant may remain osseointegrated but will lose its ability to retain the prosthesis, so that the existing prosthodontic restoration can no longer be used. The current case report describes the management of a failed Mandibular Implant Supported Overdenture.

\section{Case Report}

A 65-year-old male patient with an existing mandibular Implant Supported Overdenture (IOD) presented to the Department of Prosthodontics at Government Dental College, Kozhikode. His chief complaint was the lack of retention of the mandibular IOD. Clinical examination of the patient revealed an implant supported overdenture prosthesis retained with a ball abutment and $\mathrm{O}$ - ring attachment system since 8 years with 2 implants in the mandibular canine region (fig:1 and 2). The maxilla had been restored with a complete denture. Clinical and radiographic examination of the implant region showed that the overdenture ball abutment of both the implants were fractured at the neck region (fig:4). The screw part of the abutment remained threaded into the implant. Both implants were osseointegrated and showed no signs of peri-implantitis. Treatment options considered were: 1 . attempting to retrieve the fractured abutment, 2. removing the implant and replacing it with a new implant, 3. Abandon the implant and fabricate a conventional complete denture. Patients mandibular ridge was highly resorbed which would affect the retention and stability of the denture and the patient was not interested for second or third option. So a decision was made to attempt unscrewing of the fractured abutment.

The fractured ball abutment was retreived by putting grooves using tungsten carbide (171L) bur. The instrument was copiously cooled with water spray from the air-turbine. The abutment was unscrewed using an explorer taking care not to damage the implant. New correctly sized overdenture ball abutment ( Uniti, Equinox medical Technologies, Holland) were temporarily connected to each implant and attachment's denture base component was snapped onto the abutment ( Fig:5a and b). Preliminary impression was made with impression compound (aslate, Asian Acrylates, Mumbai) and primary cast made in plaster. Edentulous custom tray was fabricated by incorporating space for the overdenture attachment. Custom tray border molded in conventional manner with green stick ( DPI Pinnacle, Mumbai) and Secondary impression was made with addition silicone light body impression material (Zhermeck, Italy) (Fig:6). Impression material was carefully syringed around each attachment to diminish the likelihood of voids. After the impression was removed the attachment components remaining in the impression were removed and impression was beaded and boxed and poured with 
improved stone. As the attachment mechanism was incorporated in the master cast, the space allocation necessary for the attachments was accurately detailed from the beginning itself ( Fig:7 ).

Edentulous impression for the maxillary complete denture was made using conventional techniques. Record bases were made for both the cast with heat cured acrylic resin. Jaw relations were completed using standard techniques and transferred onto the semi-adjustable articulator with the help of face-bow( Fig:8). Teeth selection was done and arranged on the record base for trial denture set up. Trial denture was evaluated in patients mouth (Fig:9).After denture processing,(fig:10) the tissue surface of the mandibular denture base included the relieved areas where the attachment mechanisms were accurately transferred from the master cast. Attachment abutments were connected to their respective implants and were luted into the denture base using autopolymerising denture base material (DPI-RR cold Cure, Mumbai). Powder and liquid were mixed with a brush and placed into the attachment wells in the denture base filling them half way and firmly seated on to the mucosa. Resin was allowed to polymerize and patient was asked to bite to avoid increase in the vertical dimension. A thin layer of wax was placed over the implant surface to avoid attachment of acrylic resin over metal part (Fig:11). The attachments were fit passively without any rocking movement. Post insertion instructions and care of implants were discussed with the patient. The patient was recalled after 1 week and 1 month for examination and no peri-implant mucositis, or esthetic failures were observed, and the denture retention was satisfactory.

\section{Discussion}

Mandibular implant-supported overdentures (IODs) have provided successful therapy for edentulism.[1][2][3] Failures happening for implant-supported restorations can be related to the implant components or to the prosthesis[4][5] Technical problems related to implant components include abutment screw fractures which have been reported at an increasing rate. A review of in vivo butt-joint implant studies reported abutment screw or prosthesis screw loosening as the most frequent mechanical complication.[6] The primary reason for screw fracture is undetected screw loosening, which can be due to bruxism, an unfavourable superstructure, overloading, or malfunction.[7] The initial tensile preload generated within the screw on initial tightening provides mechanical resistance against masticatory forces. However, under functional loading, the initial tensile preload is loosened by a factor known as the settling effect.[8] In view of the importance of correct torque application in the initial phase of tightening, a torque control wrench is recommended for the procedure.[9] Additionally, implant systems with antirotational components, such as an internal hexagon, as well as those in which the abutment engages deep into the implant body, will enhance the strength of the system.[10][11]

Abutment failure due to fracture of its retaining screw is generally a challenge for the clinician due to the difficulty of removal of fractured screw fragments. Ball abutments are commonly used for patients with IODs.[12][13]Attachment wear may necessitate their replacement to maintain the efficiency of the dentures.[14] Fromentin et al reported that after 8 years of clinical wear, the mean diameter of ball abutments decreased by 22 to $31 \mu \mathrm{m}$ compared with unused components.[15] As implant parts wear, lack of intimate fit among components may pose a risk of fracture or other prosthetic complication upon removal. Therefore, clinicians must be careful to remove parts with appropriate instrumentation.

Methods for retrieving screw fragments with the implant in situ have been reported.[16][17][18] . If an abutment screw fractures above the head of the implant, hemostats or artery forceps may be used to grasp the broken screw and remove it successfully. If the fragment is not jammed, an attempt to unscrew it using an explorer or a straight probe might be successful. The tip of the instrument is moved carefully in a counterclockwise direction over the surface of the screw segment until it loosens. If the screw fracture occurs below the head of the implant or is stuck, other methods or systems can be employed to remove the fragment. Most of these systems involve drilling of a hole into the center of the broken screw followed by engaging a removal wedge into the broken screw. Reverse torque is then applied with the removal instrument. In this case report a hole was drilled into fractured abutment using tungsten carbide bur and fractured screw was removed using explorer tip. Every attempt was made to prevent the damage to the implants while removing the fractured ball abutments. New ball attachments were screwed before starting the procedure and the metal encapsulator was temporarily placed during each impression making ,thus allowing space in the final prosthesis.

Various companies have released many screw removal kits. Most were designed to remove a broken screw with a selftapping rotary instrument that could pull out the broken screw with reverse action. There are some precautions in making an access hole on top of the broken screw with the drill guide. First, only very light touch should be applied when the high-speed bur is used if not the screw could be pushed forth by bur. Second, intermittent force under abundant water spray is required so as not to generate excessive heat while making the hole. Finally, it is important to fix the drill guide at the right position while the high-speed bur is being used to make an access hole.[19] If all the methods fail to retrieve the fractured segment or there is a damage to the internal threads of the implant screw hole, a cast post and core supported prosthesis can salvage the useless 

implant[20][21].

\section{FIGURES AND TABLES}

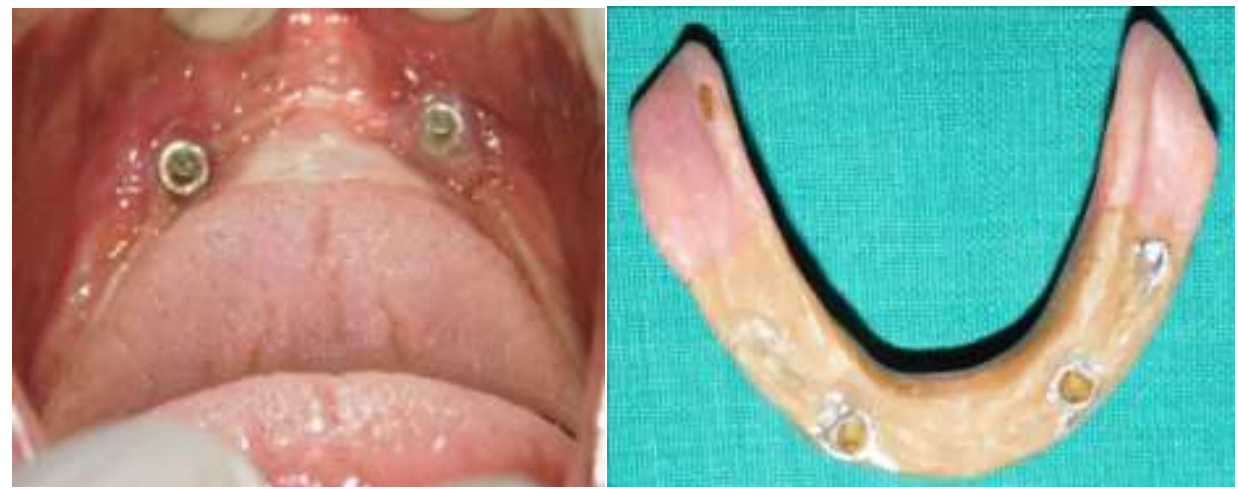

Fig. 1and 2: Intraoral view of fractured overdenture ball abutments and Existing implant supported overdenture

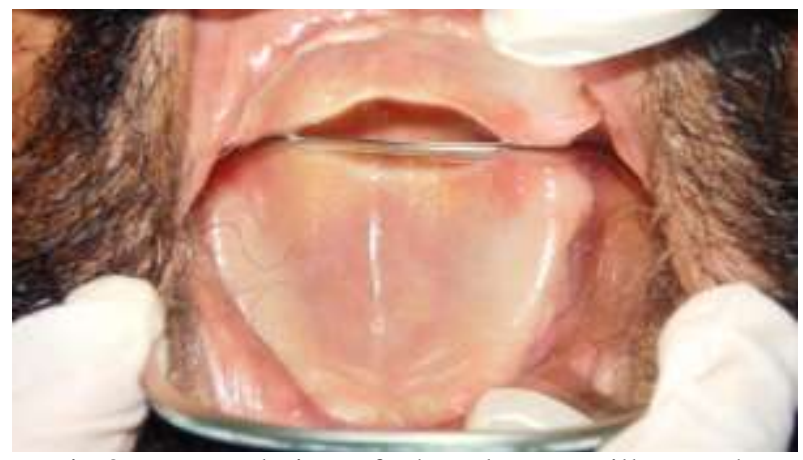

Fig. 3 : Intraoral view of edentulous maxillary arch
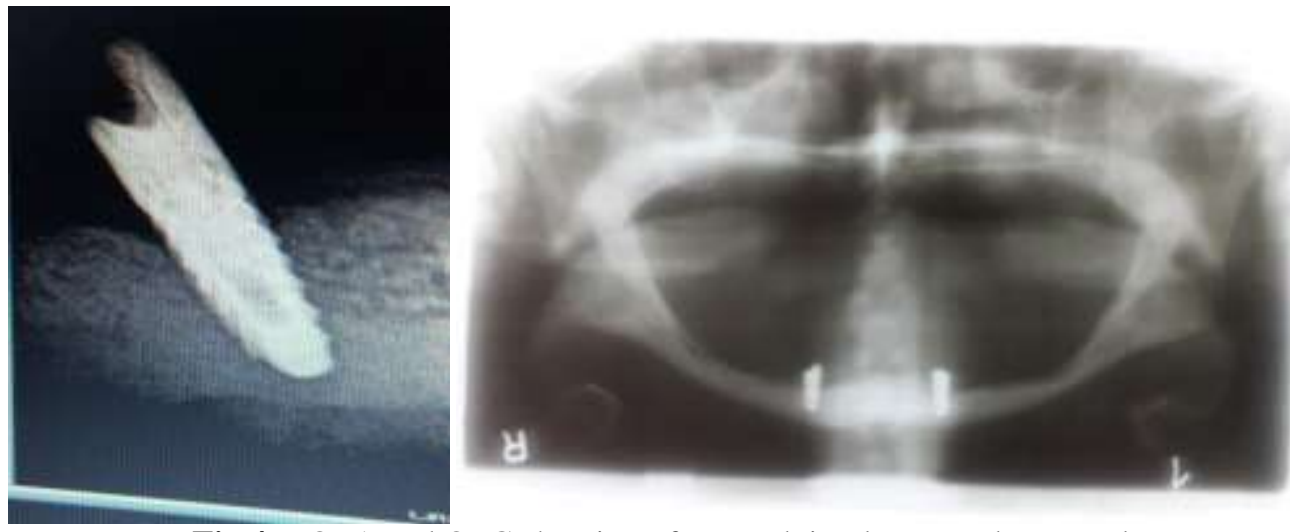

Fig.4 : IOPA and OPG showing fractured implant overdenture abutment
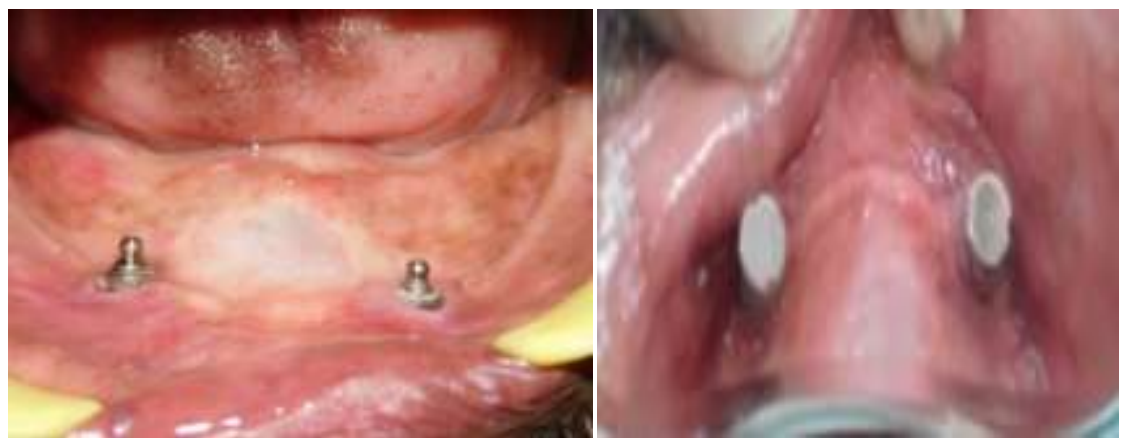

Fig. 5a and b: a. New overdenture ball abutment attached and b. with metal encapsulator 


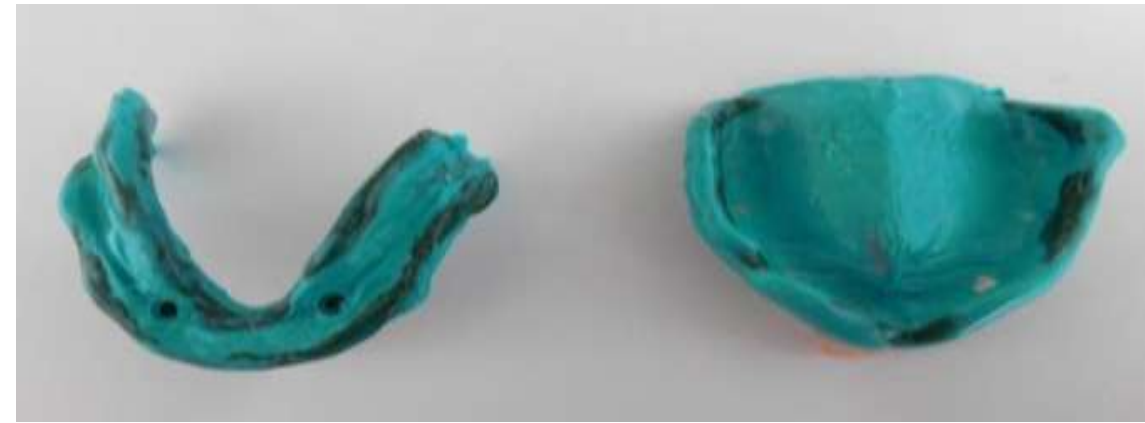

Fig. 6: Final impression of maxillary and mandibular arch.

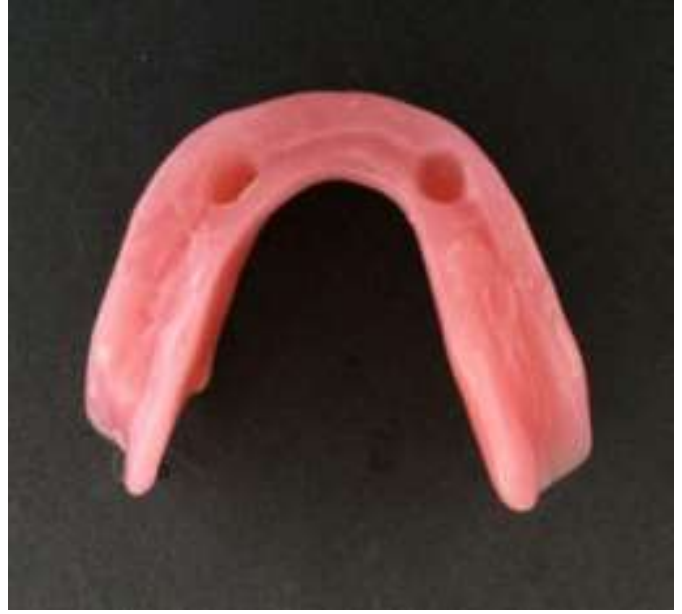

Fig.7: Mandibular permanent denture base

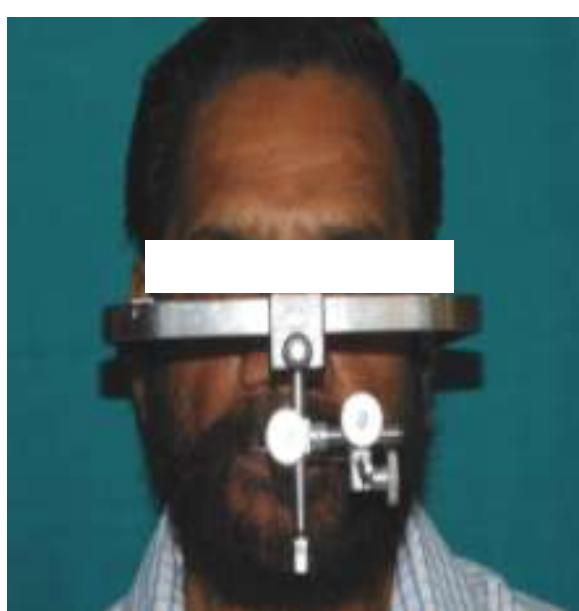

Fig.8 : Facebow transfer
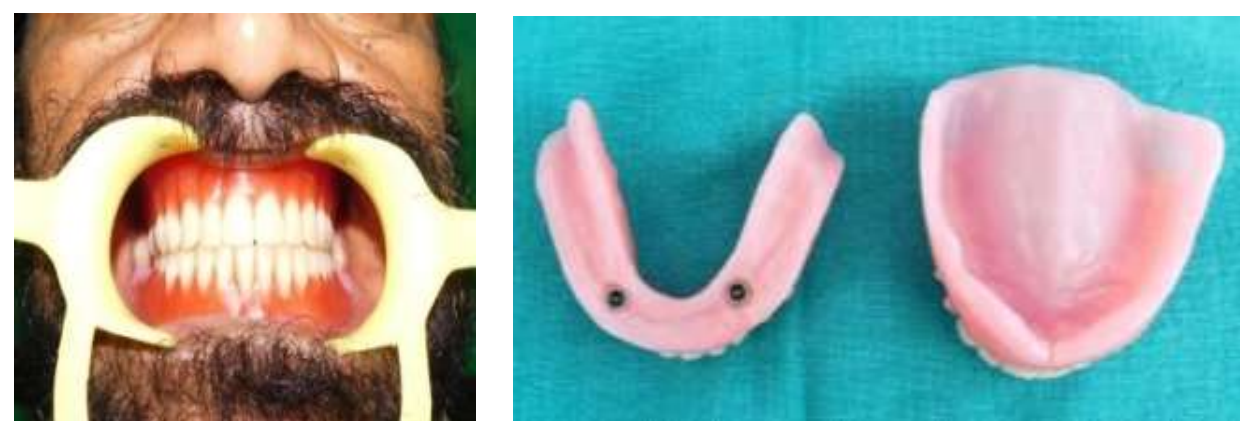

Fig.10: completed prosthesis with metal encapsulator incorporated into mandibular implant supported overdenture

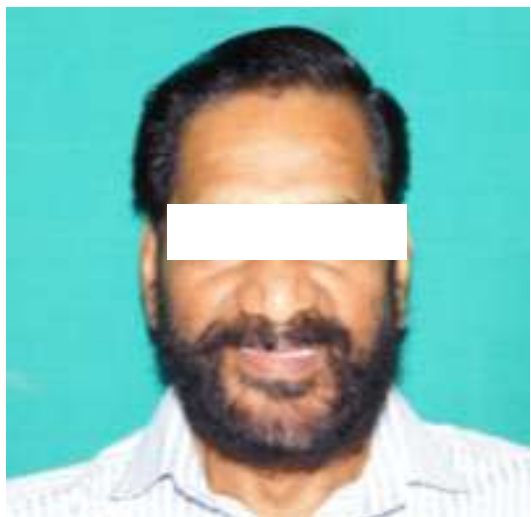

Fig.11 : Post-treatment Photograph 


\section{Conclusion}

Dental implantation is a reliable and predictable treatment for partially and completely edentulous patients and is gaining tremendous popularity and interest amongst patients and dentists alike. However, mechanical and technical complications continue to exist. Of these, one of the biggest challenges to the clinician is the conservative retrieval of fractured screw fragments from within the implants and/or abutments This clinical report described a relatively simple technique for retrieval of fractured abutment of mandibular implant supported overdenture. The technique when executed with ultimate care and precision would provide excellent result. The non-invasive nature of the procedure would also be satisfying to the patient. Therefore, clinicians who treat fractured implant abutment screw and failed implant supported overentures should keep this option in mind during treatment planning We recommend more safer and easier methods for retrieval of fractured screw abutment to be reported and practiced. Nevertheless, the aim of prosthodontic treatment should be to avoid any fracture of implant abutments. Retrieving the fractured part is important, it is perhaps even more essential to identify and eliminate causes of failure, including occlusion, premature contacts, parafunction, impassive prosthetic components,and improper fit.

\section{References}

[1]. D. R. Burns, "The mandibular complete overdenture," Dental Clinics of North America, vol. 48, no. 3. pp. 603-623, 2004

[2]. M. Melescanu Imre, M. Marin, E. Preoteasa, A. M. Tancu, and C. T. Preoteasa, "Two implant overdenture--the first alternative treatment for patients with complete edentulous mandible.," J. Med. Life, vol. 4, no. 2, pp. 207-9, 2011.

[3]. D. Harris, I. C. Benington, B. O. Connell, S. Sheridan, J. Marley, and I. C. Benington, "A comparison of implant-retained mandibular overdentures and conven- tional dentures on quality of life in edentulous patients : a randomized, prospective, withinsubject controlled clinical trial," no. Anderson 1977, pp. 1-8, 2011

[4]. P. S Calderon, P. M C Dantas, S. C L Montenegro, A. F P Carreiro, A. G R C Oliveira, E. M Dantas, and B. C V Gurgel, "Technical complications with implant-supported dental prostheses.," J. Oral Sci., vol. 56, no. 2, pp. 179-84, 2014.

[5]. T. Gonda, Y. Maeda, J. N. Walton, and M. I. MacEntee, "Fracture incidence in mandibular overdentures retained by one or two implants," J. Prosthet. Dent., vol. 103, no. 3, pp. 178-181, 2010.

[6]. C. J. Goodacre, J. Y. Kan, and K. Rungcharassaeng, "Clinical complications of osseointegrated implants.,” J. Prosthet. Dent., vol. 81 , no. 5, pp. 537-552, 1999.

[7]. I. Nergiz, P. Schmage, and R. Shahin, "Removal of a fractured implant abutment screw: A clinical report," J. Prosthet. Dent., vol. 91, no. 6, pp. 513-517, 2004

[8]. S. Winkler, K. Ring, J. D. Ring, and K. G. Boberick, "Implant screw mechanics and the settling effect: overview.," J. Oral Implantol., vol. 29, pp. 242-245, 2003.

[9]. S. Luterbacher, I. Fourmousis, N. P. Lang, and U. Brägger, "Fractured prosthetic abutments in osseointegrated implants: a technical complication to cope with.," Clin. Oral Implants Res., vol. 11, no. 2, pp. 163-170, 2000.

[10]. J. B. Brunski, D. a Puleo, and a Nanci, "Biomaterials and biomechanics of oral and maxillofacial implants: current status and future developments.," Int. J. Oral Maxillofac. Implants, vol. 15, no. 1, pp. 15-46, 2000.

[11]. L. Möllersten, P. Lockowandt, and L. Å. Lindén, "Comparison of strength and failure mode of seven implant systems: An in vitro test,” J. Prosthet. Dent., vol. 78, no. 6, pp. 582-591, 1997.

[12]. K. Gotfredsen and B. Holm, "Implant-supported mandibular overdentures retained with ball or bar attachments: a randomized prospective 5-year study.," Int. J. Prosthodont., vol. 13, no. 2, pp. 125-30, 2000.

[13]. A. E. Büttel, H. Lüthy, P. Sendi, and C. P. Marinello, "Wear of ceramic and titanium ball attachments in subjects with an implantretained overdenture: A controlled clinical trial,” J. Prosthet. Dent., vol. 107, no. 2, pp. 109-113, 2012.

[14]. M. I. MacEntee, J. N. Walton, and N. Glick, "A clinical trial of patient satisfaction and prosthodontic needs with ball and bar attachments for implant-retained complete overdentures: Three-year results," J. Prosthet. Dent., vol. 93, no. 1, pp. 28-37, 2005

[15]. O. Fromentin, C. Lassauzay, S. A. Nader, J. Feine, and R. F. De Albuquerque, "Clinical wear of overdenture ball attachments after 1, 3 and 8 years," Clin. Oral Implants Res., vol. 22, no. 11, pp. 1270-1274, 2011.

[16]. I. Nergiz, P. Schmage, R. Shahin, and O. Medicine, "Removal of a fractured implant abutment screw: A clinical report," no. June, pp. 513-517, 2004.

[17]. I. Turkyilmaz, M. J. Vierra, and N. V. Asar, "Removal of a Fractured Locator Abutment Screw Fragment,” pp. 968-972.

[18]. Y. Taira and T. Sawase, "A Modified Technique for Removing a," pp. 165-169.

[19]. J. Yoon, H. Lee, and M. Kim, "Safe Removal of a Broken Abutment Screw with Customized Drill Guide and Rotary Instrument: A Clinical Report," pp. 2-5, 2015.

[20]. K. Harshakumar, "Salvaging an Implant with Abutment Screw Fracture by a Custom Titanium Post and Core Supported Prosthesis - A Novel Technique," vol. 2, no. 1, pp. 36-39, 2014.

[21]. K. Shah and D. J. Lee, "An alternative approach for the management of fractured implant abutment screws on a mandibular implant-retained overdenture : A clinical report," J. Prosthet. Dent., vol. 115, no. 4, pp. 402-405, 2016

[22]. C. Misch, "Contemporary implant dentistry, 2nd edn,” CV Mosby, St Louis, pp. 76-194, 1999. 